\title{
Review:
}

\section{Impact of DNA mismatch repair system alterations on human fertility and related treatments"}

\author{
Min-hao HU, Shu-yuan LIU, Ning WANG, Yan WU, Fan JIN ${ }^{\dagger *}$ \\ (Key Laboratory of Reproductive Genetics (Zhejiang), Ministry of Education, and Centre of Reproductive Medicine, \\ Women's Hospital, School of Medicine, Zhejiang University, Hangzhou 310006, China) \\ "E-mail: jinfan@zju.edu.cn
}

Received June 28, 2015; Revision accepted Nov. 7, 2015; Crosschecked Dec. 16, 2015

\begin{abstract}
DNA mismatch repair (MMR) is one of the biological pathways, which plays a critical role in DNA homeostasis, primarily by repairing base-pair mismatches and insertion/deletion loops that occur during DNA replication. MMR also takes part in other metabolic pathways and regulates cell cycle arrest. Defects in MMR are associated with genomic instability, predisposition to certain types of cancers and resistance to certain therapeutic drugs. Moreover, genetic and epigenetic alterations in the MMR system demonstrate a significant relationship with human fertility and related treatments, which helps us to understand the etiology and susceptibility of human infertility. Alterations in the MMR system may also influence the health of offspring conceived by assisted reproductive technology in humans. However, further studies are needed to explore the specific mechanisms by which the MMR system may affect human infertility. This review addresses the physiological mechanisms of the MMR system and associations between alterations of the MMR system and human fertility and related treatments, and potential effects on the next generation.
\end{abstract}

Key words: DNA mismatch repair, Infertility, Assisted reproductive technology http://dx.doi.org/10.1631/jzus.B1500162

CLC number: R711.6

\section{Introduction}

Cellular DNA damage accumulates as a result of exposure to exogenous agents (biological, physical, or chemical) and endogenous sources including oxidative stress and errors associated with DNA processing. DNA damage, if unrepaired, creates the possibility of mutagenesis in somatic or germline cells, which can alter normal function and result in diseases, even in the next generation. Consequently, there are multiple mechanisms to repair DNA damage and maintain the stability of the DNA sequence in all

\footnotetext{
Corresponding author

* Project supported by the National Basic Research Programs (973) of China (Nos. 2012CB944901 and 2014CB943302), the National Natural Science Foundation of China (Nos. 81200475, 81370760, and 81571500), and the Zhejiang Provincial Natural Science Foundation of China (No. LZ13H040001)

(1D ORCID: Min-hao HU, http://orcid.org/0000-0003-0426-0275

(c) Zhejiang University and Springer-Verlag Berlin Heidelberg 2016
}

tissues and cells. One of them, known as DNA mismatch repair (MMR), mainly repairs base-pair mismatches and insertion/deletion loops (IDLs) (Jascur and Boland, 2006). MMR repairs DNA mismatches arising during replication, thereby preventing deleterious mutations and maintaining genomic stability. The MMR system also plays a critical role in the meiotic process and gametogenesis. Defects in the MMR system are related to predisposition to certain types of cancer, resistance to certain therapeutic drugs, and infertility, collectively known as DNA MMR defective abnormalities (Maduro et al., 2003; Li, 2008).

Infertility is a common and complex condition affecting about $10 \%-15 \%$ of couples of reproductive age (Gnoth et al., 2005), and the causes of a considerable proportion of infertility cases remain unknown. Based on their important physiological functions and a growing amount of evidence, MMR genes and 
proteins demonstrate an impact on human infertility, even in the next generation conceived by assisted reproductive technology (ART). The molecular mechanisms of the DNA damage and repair in spermatogenesis have been reviewed recently (Gunes et al., 2015), focusing on the process of spermatogenesis, origin of DNA damage, and five types of DNA repair mechanisms. This review will concentrate on the relationship between DNA MMR alterations and human fertility, fertility-related treatments, and the potential influence on ART offspring.

\section{Components and mechanisms of the MMR system}

First identified in Escherichia coli, MMR is a biological pathway highly conserved throughout evolution to maintain genomic integrity. The bacterial MMR system is the best studied biochemically (Lahue et al., 1989; Modrich, 1991), and yeast and mouse systems have provided valuable insights because of the power of genetic models (Kolodner and Marsischky, 1999). In humans, the MMR system is an excision and re-synthesis system that can be divided into three steps: recognition of the mismatch, excision of the incorrect fragment, and DNA re-synthesis (Table 1). The human MMR protein, MutS, which is a heterodimer composed of MutS homologues MSH2 and MSH6 (MutS $\alpha$ ) or MSH2 and MSH3 (MutS $\beta$ ), is an ATPase that plays a critical role in mismatch recognition and initiation of repair. MutS $\alpha$ preferentially recognizes base-pair mismatches and short IDLs, while MutS $\beta$ recognizes larger IDLs. Then the DNA-MutS complex recruits MutL $\alpha$, a heterodimer of MutL homologues MLH1 and PMS2. Other potential proteins like exonuclease 1 (EXO1), DNA polymerase $\delta(\operatorname{Pol} \delta)$ and its cofactors proliferation cell nuclear antigen (PCNA), and replication factor $\mathrm{C}$ (RFC) are recruited to accomplish the repair activity. Other members of the MMR system are yet to be found or confirmed such as DNA methyltransferase 1 (Dnmt1) (Guo et al., 2004; Kim et al., 2004).

In addition to DNA MMR activity, MMR is also associated with a series of DNA damage signaling pathways. Plenty of articles have reported interactions between MMR and DNA damage regulators including MLH1 and ATM (Brown et al., 2003),
MSH2 and ATR, Bcl-2 (Wang and Qin, 2003; Youn et al., 2005), MLH1, PMS2 and p53, p73 (Shimodaira et al., 2003; Chen and Sadowski, 2005), MLH1, PMS1, and PMS2 in cell cycle arrest (Stojic et al., 2005; Cannavo et al., 2007), all of which are involved in cell signaling/cycle arrest/apoptosis. Thus, the MMR system recognizes and repairs mismatches and eliminates severely damaged cells, preventing mutagenesis in the short term and tumorigenesis in the long term.

Table 1 Human MMR components and functions

\begin{tabular}{lc}
\hline \multicolumn{1}{c}{ MMR component } & Function \\
\hline MutS $\alpha$ (MSH2-MSH6) & DNA mismatch recognition \\
MutS $\beta$ (MSH2-MSH3) & \\
MutL $\alpha$ (MLH1-PMS2) & Molecular matchmaker; \\
MutL $\beta$ (MLH1-PMS1) & recruitment of other related \\
MutL $\gamma$ (MLH1-MLH3) & proteins \\
EXO1 & DNA mismatch excision \\
Pol $\delta$ & DNA re-synthesis \\
PCNA & Initiation of DNA re-synthesis \\
RFC & Loading and unloading PCNA \\
RPA & Single strand DNA protection; \\
\multicolumn{2}{c}{ termination of DNA excision } \\
DNA ligase I & Nick ligation \\
Other members unidentified \\
\hline
\end{tabular}

MMR proteins also take part in the meiotic process and are involved in gametogenesis. They have been implicated in somatic hypermutation, interstrand-crosslink repair, immunoglobulin class switching, trinucleotide repeat (TNR) expansion, and other processes. With so many proteins and regulators involved in the MMR system, it is not surprising that mistakes may occur and manifest themselves in different phenotypes. Loss of MMR function leads to failure to repair base-pair mismatches and IDLs, including short repetitive sequences known as microsatellites. Shortening or lengthening of microsatellites, referred to as microsatellite instability (MSI), is the hallmark of MMR system deficiency. The MSI status is commonly determined by five microsatellite markers (BAT25, BAT26, D2S123, D5S346, and D17S250).

The contribution of defective MMR to the development of human cancer has been recognized for more than two decades (Peltomaki, 2003). Alterations in MLH1, MSH2, MSH6, and PMS2 lead to the most common form of cancer, hereditary nonpolyposis colorectal cancer (HNPCC) or Lynch syndrome (LS). 
Loss of MMR function caused by either genetic or epigenetic variation of MMR genes is associated with various human cancers such as colorectal, endometrial, ovarian, cervical, breast, gastric, urological, skin, and other rare cancers (Watson and Lynch, 1994; Karamurzin et al., 2012). Defects in MMR can also trigger a multidrug resistance phenotype, resulting cellular resistance to certain alkylating, methylating, and platinating agents, antimetabolites, topoisomerase inhibitors, and DNA minor groove binders (Valentini et al., 2006) since the system is involved in DNA repair, cell cycle arrest, and many other metabolic pathways. In addition to its involvement in human cancer and drug resistance, the role of the MMR system in the meiotic process and gametogenesis should never be neglected. MMR alterations could manifest themselves in human infertility and infertility treatment. More research is needed to understand the origin and development of infertility.

\section{MMR alterations and infertility}

Infertility is a worldwide problem that occurs in $10 \%-15 \%$ of couples. Male factors account for about half of all infertility cases. However, the etiology of male infertility remains unknown in about half of all cases. Such cases are classified as idiopathic. This is particularly relevant to men with non-obstructive azoospermia or severe oligospermia. The human testis is composed mainly of three types of cells: spermatogenic cells to produce spermatids; Sertoli cells to protect, support, and supply spermatogenic cells, making sure that spermatids are well produced; and Leydig cells to secrete androgen. Male infertility could be an outcome of genetic, epigenetic, endocrine, or environmental changes that lead to aberrant sperm production or function. Substantial evidence has indicated that several members of the MMR family participate in the meiotic recombination process and gametogenesis (Kunkel and Erie, 2005; Iyer et al., 2006; Jiricny, 2006). A defective MMR system has been shown to be related to spermatogenetic failure and spermatic dysfunction in some infertile individuals and animal models (Mukherjee et al., 2010). Later, we will discuss recent progress in understanding the genetic and epigenetic variation in the MMR system associated with male infertility.
Animal knockout models have shown the importance of MMR genes in both male and female infertility. First discovered in 1995, mice with defective PMS2 exhibit male infertility due to failure of chromosomal synapsis (Baker et al., 1995). Disruption of other genes, including $M L H 1, M L H 3$, and EXO1 (Baker et al., 1996; Lipkin et al., 2002; Wei et al., 2003), also leads to phenotypes of infertility (Table 2). However, there has been little progress in understanding links between the MMR system and human male infertility. Maduro et al. (2003) proposed that MSI and defective MMR proteins like MLH1 and $\mathrm{MSH} 2$ are presented in both testicular and peripheral blood cells in some azoospermic men, predominantly in Sertoli cell-only patients. This indicates that defects in MMR may underlie some forms of male infertility such as Sertoli cell-only, hypospermatogenesis type, and maturation arrest. Recently, Sertoli cells have been recognized as having several common metabolic features analogous to those of cancer cells and could be used as a good model for exploring new perspectives of the Warburg effect (Oliveira et al., 2015). Sertoli cells may play a significant role in obesity-induced male infertility (Martins et al., 2015). The above studies signify important linkages between MMR alterations and human infertility and Sertoli cells, which deserve further detailed study.

Table 2 MMR genes involved in mouse infertility models

\begin{tabular}{cl}
\hline Gene & \multicolumn{1}{c}{ Phenotype } \\
\hline MSH4 & $\begin{array}{c}\text { Infertile: failure of spermatogonial matura- } \\
\text { tion beyond zygonema } \\
\text { Infertile: incomplete and non-homologous } \\
\text { chromosomal pairing }\end{array}$ \\
& $\begin{array}{c}\text { Infertile: failure of crossing over } \\
\text { MLH1 }\end{array}$ \\
PMS2 & $\begin{array}{c}\text { Male infertile: disruption of normal chro- } \\
\text { mosomal synapsis }\end{array}$ \\
MLH3 & Infertile \\
EXO1 & Infertile \\
\hline
\end{tabular}

MMR proteins participate in the meiotic recombination process in yeast and mammals. Among these proteins there are two MutS homologues (MSH4, MSH5) and three MutL homologues (MLH1, MLH3, PMS2) (Surtees et al., 2004; Her et al., 2007). Terribas et al. (2010) studied 13 infertile patients each with one of two types of spermatogenic arrest: maturation arrest or hypospermatogenesis. These two types showed significantly decreased MMR expression 
values (MLH1, MLH3, MSH4, MSH5) in testicular samples, except for PMS2, and the more serious type, the maturation arrest group, showed a greater reduction. Ferras et al. (2007) showed that the testicular $M L H 3$ gene in 13 infertile patients with spermatogenic arrest contained four missense (T2896C, $\mathrm{C} 2531 \mathrm{~T}$ ) and eight intronic (IVS9+66G/A) variants. Among these 13 patients, the combination of $\mathrm{C} 2531 \mathrm{~T}$ and IVS9+66G/A variants was identified only in patients with primary spermatogenic arrest, indicating that the presence of two simultaneous $M L H 3$ variants might be a cause of the arrest. MLH3 is certainly involved in the mammalian meiotic process, but its role in MMR during DNA replication is controversial (Lipkin et al., 2000; Wu et al., 2001; Hienonen et al., 2003; Liu et al., 2003; Korhonen et al., 2007). Cytological studies in mice have shown that MLH3 is found in zygotene, combines with recombination nodules in early pachytene, and associates with MLH1 from mid-pachytene to the early diplonema stages (Lipkin et al., 2002; Santucci-Darmanin et al., 2002; Marcon and Moens, 2003). Also, both male and female $\mathrm{MLH}^{-/-}$mice manifested infertility (Lipkin et al., 2002). Therefore, human $M L H 3$ variants might interfere in the meiotic process resulting in male infertility.

Ferras et al. (2012) found that one patient with two MLH3 mutations, the combination of C2531T and IVS9+66G/A, showed overexpression of MLH3 and MLH1. Since MLH3 and PMS2 share the same interaction domain on MLH1, it is possible that the quantitative balance of the MLH1-binding partners (MLH3 and PMS2) plays a crucial role in specifying different outcomes during meiosis (Kondo et al., 2001; Korhonen et al., 2007). Accordingly, mutationrelated overexpression of MLH3 and MLH1 may result in a predominance of MLH1-MLH3 complexes and a relative reduction in MLH1-PMS2 complexes. Consequently, meiotic failure might occur as MLH1PMS2 complexes ought to replace MLH1-MLH3 complexes during diplonema. However, due to the relatively small sample sizes in the above studies, further evaluation of the correlations and mechanisms linking MMR defects and male infertility is required.

Recently, numerous sequencing analyses of single nucleotide polymorphisms (SNPs) in candidate genes have helped to clarify the etiology and susceptibility of both male and female infertility (Kang et al.,
2014; Ni et al., 2014). Xu et al. (2010) identified two SNPs, MSH5 (C85T, Pro29Ser) and MLH3 (C2531T, Pro844Leu) associated with male infertility, especially in non-obstructive azoospermia or severe oligozoospermia. The allele carriers MSH5 Pro29Ser and MLH3 Pro844Leu demonstrated a 2.89-fold and 2.25 -fold increased risk of azoospermia or oligozoospermia, respectively. However, two major problems have limited the value of medical sequencing studies. First, the actual rates of these reported SNPs are quite low and could explain only a small percentage of idiopathic male infertility. Growing evidence suggests that common genetic variations are rarely responsible for the whole disease phenotype (Frazer et al., 2009; Manolio et al., 2009). The "common disease, common variant" model is not suitable for most complex diseases, including male infertility. Further studies have suggested that risk or causative genetic variants for most cases of idiopathic male infertility might be related to the identification of rare polymorphisms and copy number variants (CNVs). Second, most reports of SNPs associated with male infertility have either not been followed up with validation studies, or often failed validation in follow-up studies.

Ji et al. (2012) conducted a prospective casecontrol study of 1292 idiopathic male infertility patients and 480 fertile controls in a Chinese population. The idiopathic infertility patients were divided into two subgroups: 524 patients with non-obstructive azoospermia or oligozoospermia and 768 with a normal sperm count. Twenty-one tagging SNPs in five MMR genes (MLH1, MLH3, PMS2, MSH4, and MSH5) were examined by the sequence detection system and the SNPstream 12-plex platform. The results showed that the genotype frequencies of three SNPs, MLH1 (rs4647269), PMS2 (rs1059060, Ser775Asn), and MSH5 (rs2075789, Pro29Ser), were significantly increased (by from $6 \%$ to $17 \%$ ) in patients with azoospermia or oligozoospermia. Therefore, the presence of these SNPs seems to be a risk factor for the development of azoospermia or oligozoospermia. Another SNP in PMS2 rs1059060 appeared to contribute to the risk of male infertility in patients with a normal sperm count. Guerrette et al. (1999) localized the MLH1-PMS2 interaction region to amino acids $506-675$ of MLH1 and $675-850$ of PMS2. This study provided evidence that the PMS2 
Ser775Asn variant attenuates the binding of MLH1 and PMS2 detected by fluorescence resonance energy transfer (FRET) and co-immunoprecipitation assay, further supporting the potential interaction between MLH1-PMS2 and MLH1-MLH3 discussed above. The MSH5 Pro29Ser polymorphism is located within the MSH4-MSH5 interacting domain and leads to a weakened formation of the MSH4-MSH5 heterocomplex (Yi et al., 2005). This was supported by the study of Xu et al. (2010). Gene knockout of MSH4 or MSH5 results in infertility in mice since they are unable to resolve meiotic chromosomal crossovers (de Vries et al., 1999; Edelmann et al., 1999; Kneitz et al., 2000). Consequently, MSH5 Pro29Ser alteration is related to a significantly increased risk of male infertility. However, the detailed molecular mechanisms are unknown.

Compared with the current understanding of the MMR system in male infertility, its potential involvement in female infertility has received much less attention. A case-control study including 41 women with premature ovarian failure and 39 controls suggested that MSH5 Pro29Ser polymorphism might be an explanation for premature ovarian failure (Mandon-Pepin et al., 2008), indicating that MMR gene mutation is likely to be related to female infertility. Pashaiefar et al. (2013) suggested that MLH3 C2531T polymorphism can be associated with the risk of unexplained fertility in Iranian women. Perry et al. (2014) showed that gene mutation-related low expression of MSH6 due to one SNP in MSH6 (rs1800932) is associated with earlier menopause, suggesting that MMR is a key process in determining female reproductive lifespan and could be a crucial therapeutic target for female infertility.

With an increased incidence and a younger age of patients, certain forms of MMR-related genital system cancers which require surgical treatment may contribute to female "structural" infertility. For instance, endometrial cancer has an intimate connection with genetic and epigenetic variation of the MMR system. Studies demonstrated that aberrant methylation of $M L H 1$ is detected in about $40 \%$ of endometrial cancer cases and is considered to be an important process in the early stage of endometrial carcinogenesis (Muraki et al., 2009). Conservative surgical and hormonal therapy is currently practical in clinical treatment. This kind of therapy ensures that a con- siderable proportion of women with endometrial cancer successfully achieve pregnancies resulting in live births with or without ART (Park et al., 2013). However, some other problems still exist. Although current studies have demonstrated that there is no definitive evidence of a significant association between MMR status and survival in endometrial cancer (Diaz-Padilla et al., 2013), deficient MMR is associated with a higher risk of high-grade endometrial cancer and worse clinical outcomes in women aged 40 years or younger (Garg et al., 2009; Shih et al., 2011). Also, MMR status appears to be linked to body mass index (BMI) and endometrial cancer (Win et al., 2011; Joehlin-Price et al., 2014), indicating a possible interactive system between MMR and some types of metabolic diseases and cancers. Therefore, cautious and comprehensive assessment should be carried out before, during, and after conservative therapy in young women who have a strong desire to preserve fertility, to maintain the safety and health of both the mother and offspring.

Apart from the genetic components involved in human infertility, a growing body of evidence clearly indicates the importance of other factors such as epigenetic variation (Dada et al., 2012; Richardson et al., 2014). Whether epigenetic variation in the MMR system may be etiologic of infertility is unknown, but the fast developing field of epigenetics may be yet another area related to infertility and should be considered together with genetic factors.

\section{MMR alterations and ART}

With the application of ART including in vitro fertilization (IVF), intracytoplasmic sperm injection (ICSI), and preimplantation genetic diagnosis (PGD), it is now practical to bypass the natural barriers to produce offspring. Interestingly, Terribas et al. (2010) considered the expression of testicular MSH4 could be useful as a surrogate marker for intratesticular elongated spermatids in patients with non-obstructive azoospermia and may be useful in predicting the viability of assisted reproduction. This approach needs further evaluation for sperm quality selection. Zheng et al. (2005) showed that in vitro culture could lead to dysregulation of many genes and possibly affect the expression of MSH2, which may affect the viability 
of Rhesus monkey embryos. This raises the possibility of the same possible biological activity in humans and implies that the MMR system might play a role in the ART process and affect the outcome. ART offspring are associated with various risks such as preterm delivery, low birth weight, congenital abnormality, and genomic imprinting syndromes (Maher et al., 2003; Kurinczuk et al., 2004; de Ligt et al., 2012). However, it is difficult to establish whether these risks are related to the technology itself or the inherited genetic background. Whether the incidence of congenital abnormalities increases following ART is controversial (Halliday et al., 2010; Simon et al., 2010; Woldringh et al., 2010).

ART has been shown to have a definite relationship with an increased number of genetic and epigenetic alterations (Kochanski et al., 2013). ART may create de novo mutations through diverse chromosomal and molecular mechanisms. It enables the transmission of pre-existing mutations which are related to infertility and the natural process of early pregnancy termination. A Y-chromosome microdeletion is found in about 1 in 4000 in the general population and is responsible for male infertility. Feng et al. (2008) proposed that ART offspring may show a rising risk of a gene static mutation, azoospermia factor (AZF) microdeletion, even when their fathers have a normal spermatogenesis and genetic background. Bianchi et al. (2002) showed that Y chromosome MSI and AZF microdeletion testing in five cases of HNPCC strongly suggested a correlation between heterozygosity for $M L H 1$ or other MMR gene mutations, Y chromosome instability, and AZF microdeletions. Thus, MMR gene mutations may play a role in the origin of AZF microdeletions. Given the fact of increased vertical transmission of Ychromosome microdeletions in the offspring via ICSI (Serebrovska et al., 2006), the potential benefits and risks of adopting ART for those specific individuals who carry defective MMR genes should be considered.

Zheng et al. (2013) indicated that ART conceived babies display an increased incidence of gene dynamic mutation, also defined as TNR instability, which is related to more than 20 neuromuscular and neurodegenerative disorders including Huntington's disease, myotonic dystrophy, and fragile $\mathrm{X}$ syndrome. Due to the specificity of TNR structure, the DNA damage repair system plays an important role in the formation of TNR alterations, except for its function in repairing de novo mutations (Fig. 1). As MMR protein expression can alter TNR in diverse ways by either enhancing or suppressing different human TNR types (Lin and Wilson, 2009; Halabi et al., 2012; Pluciennik et al., 2013), ART application should be considered more cautiously to prevent severe diseases.
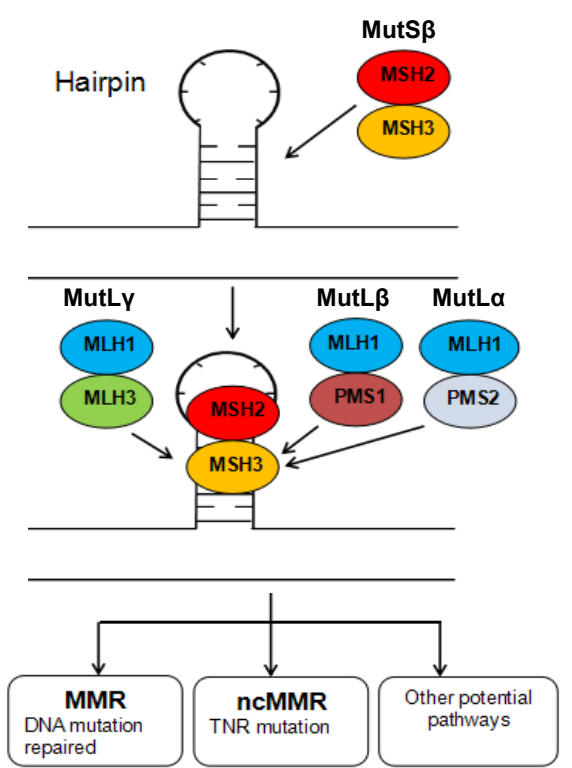

Fig. 1 Proposed function model of MutS and MutL in relation to TNR instability

TNR-related hairpin structure occurring during DNA replication is initially recognized by the MutS $\beta$ complex, and then the MutL complex is recruited. Various pathways including canonical MMR and noncanonical MMR (ncMMR) may be engaged, leading to different outcomes of TNR instability: DNA damage repaired in time or otherwise, eventual TNR mutation

As for epigenetic variation, possible risks related to ART may be caused by either the use of incomplete reprogrammed sperm or in vitro embryo culture during a time of epigenetic reprogramming (Lucifero et al., 2004; Niemitz and Feinberg, 2004; Thompson and Williams, 2005). Geneticists have reported an increased incidence of selected epigenetic defects in ART offspring, such as Beckwith-Weidemann syndrome and Angelman syndrome (Maher et al., 2003; de Ligt et al., 2012). Although there is no evidence that the MMR system is involved in the epigenetic stability of ART offspring, we can assume that there might be an interaction since both MMR and epigenetic biological mechanisms are extremely active during gametogenesis and embryonic development. 
Our unpublished data show that ART procedures and the infertility background might affect MMR epigenetic modifications like DNA methylation. This needs further investigation.

Studies in mice and humans have reported that some genetic and epigenetic modifications caused by ART can be transmitted to the next or even to the $F_{2}$ generation (van Montfoort et al., 2012; Wang et al., 2013). However, there have been no reports of transgenerational effects caused by MMR alterations. In consideration of its function in the parental generation, the inheritance of abnormal MMR gene status might affect aspects of an offspring's health condition including predisposition to certain types of cancer, resistance to certain therapeutic drugs, and infertility. This area needs further study.

Given that the above, augmented genetic mutations seen in infertile individuals may raise the probability of these variants being inherited, conferring increased risk of infertility and then possible somatic diseases in later life in ART offspring. Research has shown that epigenetic mechanisms not only lead to inappropriate expression of the affected gene but may also expose hidden genetic variation, contributing to a predisposition to epigenetic instability in offspring conceived by ART (Sollars et al., 2003). Alternatively, the ART procedures and the genetic background may alter the genetic and epigenetic status of these offspring. More detailed information about infertility-related factors, gene mutations, DNA SNPs, other genetic and epigenetic forms of the MMR system, and correlated biomarkers should be found and ultimately applied clinically to provide better counseling and treatment for infertile couples considering IVF, ICSI, or even PGD, which aims to avoid inheriting defective genes. Also, long term follow-up studies of children born from ART are required to understand the possible effects on these offspring.

\section{Conclusions}

Apart from its primary role to correct replicationassociated base-pair mismatches and IDLs, MMR also plays a crucial role in DNA recombination and is involved in gametogenesis. Infertility is an extremely complex disorder caused by various genetic, epige- netic, endocrine, and environmental factors. Although the etiology of human infertility is still largely unknown, the impact of genetic and epigenetic MMR system alterations on infertility is beyond debate. However, further studies are required to elucidate the molecular mechanisms of MMR genes and other additive risk factors in infertility. A better understanding of MMR alterations might be helpful in reducing DNA damage, developing gene targeted therapy, and providing diagnostic applications for ART.

The diverse functions of the MMR system in the human body, the applicability to humans of research based on transgenic, knock-out or knock-in mice models, and the great difficulty in obtaining and ethically using human gametes, especially oocytes and embryos, are huge obstacles to improving our understanding of MMR mechanisms in human infertility. More than thirty years of ART application and thirtysix years of observation of the first "in vitro" baby are still insufficient to thoroughly understand the potential changes and risks in later life resulting from infertility treatments. More work is urgently needed to investigate the interaction between MMR alterations and DNA integrity, human infertility, and ART security, to establish a better medical system with improved preventive, diagnostic, and therapeutic treatments of human infertility.

There is no doubt that ART will continue to be a major medical approach for infertile couples. Much work remains to be done to maximize the safety and reduce the risks of ART offspring. Long-term followup programs will yield significant results for fertility specialists providing ART, neonatologists working with ART offspring and geneticists counseling infertile parents. The efforts of global scientists, increasing maturity of the ART process, and the development of scientific technologies such as microarrays and single cell level sequencing, will lead to a better understanding of the cellular and molecular mechanisms of the MMR system involved in human infertility and related treatments. This will provide a better perspective to improve diagnostic capability, patient care, and ultimately the quality of the offspring.

\section{Compliance with ethics guidelines}

Min-hao HU, Shu-yuan LIU, Ning WANG, Yan WU, and Fan JIN declare that they have no conflict of interest. 
This article does not contain any studies with human or animal subjects performed by any of the authors.

\section{References}

Baker, S.M., Bronner, C.E., Zhang, L., et al., 1995. Male mice defective in the DNA mismatch repair gene PMS2 exhibit abnormal chromosome synapsis in meiosis. Cell, 82(2): 309-319.

http://dx.doi.org/10.1016/0092-8674(95)90318-6

Baker, S.M., Plug, A.W., Prolla, T.A., et al., 1996. Involvement of mouse Mlhl in DNA mismatch repair and meiotic crossing over. Nat. Genet., 13(3):336-342. http://dx.doi.org/10.1038/ng0796-336

Bianchi, N.O., Richard, S.M., Peltomaki, P., et al., 2002. Mosaic AZF deletions and susceptibility to testicular tumors. Mutat. Res., 503(1-2):51-62. http://dx.doi.org/10.1016/S0027-5107(02)00072-6

Brown, K.D., Rathi, A., Kamath, R., et al., 2003. The mismatch repair system is required for S-phase checkpoint activation. Nat. Genet., 33(1):80-84. http://dx.doi.org/10.1038/ng1052

Cannavo, E., Gerrits, B., Marra, G., et al., 2007. Characterization of the interactome of the human MutL homologues MLH1, PMS1, and PMS2. J. Biol. Chem., 282(5):29762986.

http://dx.doi.org/10.1074/jbc.M609989200

Chen, J., Sadowski, I., 2005. Identification of the mismatch repair genes PMS2 and MLH1 as p53 target genes by using serial analysis of binding elements. PNAS, 102(13): 4813-4818.

http://dx.doi.org/10.1073/pnas.0407069102

Dada, R., Kumar, M., Jesudasan, R., et al., 2012. Epigenetics and its role in male infertility. J. Assist. Reprod. Genet., 29(3):213-223.

http://dx.doi.org/10.1007/s10815-012-9715-0

de Ligt, J., Willemsen, M.H., van Bon, B.W., et al., 2012. Diagnostic exome sequencing in persons with severe intellectual disability. N. Engl. J. Med., 367(20):1921-1929. http://dx.doi.org/10.1056/NEJMoa1206524

de Vries, S.S., Baart, E.B., Dekker, M., et al., 1999. Mouse MutS-like protein Msh5 is required for proper chromosome synapsis in male and female meiosis. Genes. Dev., 13(5):523-531. http://dx.doi.org/10.1101/gad.13.5.523

Diaz-Padilla, I., Romero, N., Amir, E., et al., 2013. Mismatch repair status and clinical outcome in endometrial cancer: a systematic review and meta-analysis. Crit. Rev. Oncol. Hematol., 88(1):154-167. http://dx.doi.org/10.1016/j.critrevonc.2013.03.002

Edelmann, W., Cohen, P.E., Kneitz, B., et al., 1999. Mammalian MutS homologue 5 is required for chromosome pairing in meiosis. Nat. Genet., 21(1):123-127. http://dx.doi.org/10.1038/5075

Feng, C., Wang, L., Dong, M., et al., 2008. Assisted reproductive technology may increase clinical mutation detection in male offspring. Fertil. Steril., 90(1):92-96. http://dx.doi.org/10.1016/j.fertnstert.2007.06.004

Ferras, C., Zhou, X.L., Sousa, M., et al., 2007. DNA mismatch repair gene $h M L H 3$ variants in meiotic arrest. Fertil. Steril., 88(6): 1681-1684.

http://dx.doi.org/10.1016/j.fertnstert.2007.01.063

Ferras, C., Fernandes, S., Silva, J., et al., 2012. Expression analysis of MLH3, MLH1, and MSH4 in maturation arrest. Reprod. Sci., 19(6):587-596. http://dx.doi.org/10.1177/1933719111428521

Frazer, K.A., Murray, S.S., Schork, N.J., et al., 2009. Human genetic variation and its contribution to complex traits. Nat. Rev. Genet., 10(4):241-251.

http://dx.doi.org/10.1038/nrg2554

Garg, K., Shih, K., Barakat, R., et al., 2009. Endometrial carcinomas in women aged 40 years and younger: tumors associated with loss of DNA mismatch repair proteins comprise a distinct clinicopathologic subset. Am. J. Surg. Pathol., 33(12):1869-1877. http://dx.doi.org/10.1097/PAS.0b013e3181bc9866

Gnoth, C., Godehardt, E., Frank-Herrmann, P., et al., 2005. Definition and prevalence of subfertility and infertility. Hum. Reprod., 20(5):1144-1147. http://dx.doi.org/10.1093/humrep/deh870

Guerrette, S., Acharya, S., Fishel, R., 1999. The interaction of the human MutL homologues in hereditary nonpolyposis colon cancer. J. Biol. Chem., 274(10):6336-6341. http://dx.doi.org/10.1074/jbc.274.10.6336

Gunes, S., Al-Sadaan, M., Agarwal, A., 2015. Spermatogenesis, DNA damage and DNA repair mechanisms in male infertility. Reprod. BioMed. Online, 31(3):309-319. http://dx.doi.org/10.1016/j.rbmo.2015.06.010

Guo, G., Wang, W., Bradley, A., 2004. Mismatch repair genes identified using genetic screens in Blm-deficient embryonic stem cells. Nature, 429(6994):891-895. http://dx.doi.org/10.1038/nature02653

Halabi, A., Ditch, S., Wang, J., et al., 2012. DNA mismatch repair complex MutS $\beta$ promotes GAA·TTC repeat expansion in human cells. J. Biol. Chem., 287(35):2995829967. http://dx.doi.org/10.1074/jbc.M112.356758

Halliday, J.L., Ukoumunne, O.C., Baker, H.W., et al., 2010. Increased risk of blastogenesis birth defects, arising in the first 4 weeks of pregnancy, after assisted reproductive technologies. Hum. Reprod., 25(1):59-65. http://dx.doi.org/10.1093/humrep/dep364

Her, C., Zhao, N., Wu, X., et al., 2007. MutS homologues hMSH4 and hMSH5: diverse functional implications in humans. Front. Biosci., 12(1):905-911. http://dx.doi.org/10.2741/2112

Hienonen, T., Laiho, P., Salovaara, R., et al., 2003. Little evidence for involvement of MLH3 in colorectal cancer predisposition. Int. J. Cancer., 106(2):292-296. http://dx.doi.org/10.1002/ijc.11218

Iyer, R.R., Pluciennik, A., Burdett, V., et al., 2006. DNA mismatch repair: functions and mechanisms. Chem. Rev., 106(2):302-323. http://dx.doi.org/10.1021/cr0404794 
Jascur, T., Boland, C.R., 2006. Structure and function of the components of the human DNA mismatch repair system. Int. J. Cancer., 119(9):2030-2035. http://dx.doi.org/10.1002/ijc.22023

Ji, G., Long, Y., Zhou, Y., et al., 2012. Common variants in mismatch repair genes associated with increased risk of sperm DNA damage and male infertility. BMC Med., 10(1):49.

http://dx.doi.org/10.1186/1741-7015-10-49

Jiricny, J., 2006. The multifaceted mismatch-repair system. Nat. Rev. Mol. Cell. Biol., 7(5):335-346. http://dx.doi.org/10.1038/nrm1907

Joehlin-Price, A.S., Perrino, C.M., Stephens, J., et al., 2014. Mismatch repair protein expression in 1049 endometrial carcinomas, associations with body mass index, and other clinicopathologic variables. Gynecol. Oncol., 133(1):43-47. http://dx.doi.org/10.1016/j.ygyno.2014.01.017

Kang, S., Li, Y., Li, B., et al., 2014. Genetic variation of the E-cadherin gene is associated with primary infertility in patients with ovarian endometriosis. Fertil. Steril., 102(4): 1149-1154. http://dx.doi.org/10.1016/j.fertnstert.2014.07.005

Karamurzin, Y., Zeng, Z., Stadler, Z.K., et al., 2012. Unusual DNA mismatch repair-deficient tumors in Lynch syndrome: a report of new cases and review of the literature. Hum. Pathol., 43(10):1677-1687. http://dx.doi.org/10.1016/j.humpath.2011.12.012

Kim, M., Trinh, B.N., Long, T.I., et al., 2004. Dnmt1 deficiency leads to enhanced microsatellite instability in mouse embryonic stem cells. Nucleic Acids Res., 32(19): 5742-5749. http://dx.doi.org/10.1093/nar/gkh912

Kneitz, B., Cohen, P.E., Avdievich, E., et al., 2000. MutS homolog 4 localization to meiotic chromosomes is required for chromosome pairing during meiosis in male and female mice. Genes Dev., 14(9):1085-1097. http://dx.doi.org/10.1101/gad.14.9.1085

Kochanski, A., Merritt, T.A., Gadzinowski, J., et al., 2013. The impact of assisted reproductive technologies on the genome and epigenome of the newborn. J. Neonatal. Perinatal. Med., 6(2):101-108. http://dx.doi.org/10.3233/NPM-1366812

Kolodner, R.D., Marsischky, G.T., 1999. Eukaryotic DNA mismatch repair. Curr. Opin. Genet. Dev., 9(1):89-96. http://dx.doi.org/10.1016/S0959-437X(99)80013-6

Kondo, E., Horii, A., Fukushige, S., 2001. The interacting domains of three MutL heterodimers in man: hMLH1 interacts with 36 homologous amino acid residues within hMLH3, hPMS1 and hPMS2. Nucleic Acids. Res., 29(8): 1695-1702. http://dx.doi.org/10.1093/nar/29.8.1695

Korhonen, M.K., Raevaara, T.E., Lohi, H., et al., 2007. Conditional nuclear localization of hMLH3 suggests a minor activity in mismatch repair and supports its role as a lowrisk gene in HNPCC. Oncol. Rep., 17(2):351-354. http://dx.doi.org/10.3892/or.17.2.351
Kunkel, T.A., Erie, D.A., 2005. DNA mismatch repair. Annu. Rev. Biochem., 74(1):681-710. http://dx.doi.org/10.1146/ annurev.biochem.74.082803.133243

Kurinczuk, J.J., Hansen, M., Bower, C., 2004. The risk of birth defects in children born after assisted reproductive technologies. Curr. Opin. Obstet. Gynecol., 16(3):201-209. http://dx.doi.org/10.1097/00001703-200406000-00002

Lahue, R.S., Au, K.G., Modrich, P., 1989. DNA mismatch correction in a defined system. Science, 245(4914): 160-164. http://dx.doi.org/10.1126/science. 2665076

Li, G.M., 2008. Mechanisms and functions of DNA mismatch repair. Cell Res., 18(1):85-98. http://dx.doi.org/10.1038/cr.2007.115

Lin, Y., Wilson, J.H., 2009. Diverse effects of individual mismatch repair components on transcription-induced CAG repeat instability in human cells. DNA Repair (Amst), 8(8):878-885. http://dx.doi.org/10.1016/j.dnarep.2009.04.024

Lipkin, S.M., Wang, V., Jacoby, R., et al., 2000. MLH3: a DNA mismatch repair gene associated with mammalian microsatellite instability. Nat. Genet., 24(1):27-35. http://dx.doi.org/10.1038/71643

Lipkin, S.M., Moens, P.B., Wang, V., et al., 2002. Meiotic arrest and aneuploidy in MLH3-deficient mice. Nat. Genet., 31(4):385-390. http://dx.doi.org/10.1038/ng931

Liu, H.X., Zhou, X.L., Liu, T., et al., 2003. The role of hMLH3 in familial colorectal cancer. Cancer. Res., 63(8):18941899.

Lucifero, D., Mann, M.R., Bartolomei, M.S., et al., 2004. Gene-specific timing and epigenetic memory in oocyte imprinting. Hum. Mol. Genet., 13(8):839-849. http://dx.doi.org/10.1093/hmg/ddh104

Maduro, M.R., Casella, R., Kim, E., et al., 2003. Microsatellite instability and defects in mismatch repair proteins: a new aetiology for Sertoli cell-only syndrome. Mol. Hum. Reprod., 9(2):61-68. http://dx.doi.org/10.1093/molehr/gag013

Maher, E.R., Afnan, M., Barratt, C.L., 2003. Epigenetic risks related to assisted reproductive technologies: epigenetics, imprinting, ART and icebergs? Hum. Reprod., 18(12): 2508-2511. http://dx.doi.org/10.1093/humrep/deg486

Mandon-Pepin, B., Touraine, P., Kuttenn, F., et al., 2008. Genetic investigation of four meiotic genes in women with premature ovarian failure. Eur. J. Endocrinol., 158(1):107-115. http://dx.doi.org/10.1530/EJE-07-0400

Manolio, T.A., Collins, F.S., Cox, N.J., et al., 2009. Finding the missing heritability of complex diseases. Nature, 461(7265):747-753. http://dx.doi.org/10.1038/nature08494

Marcon, E., Moens, P., 2003. MLH1p and MLH3p localize to precociously induced chiasmata of okadaic-acid-treated mouse spermatocytes. Genetics, 165(4):2283-2287. 
Martins, A.D., Moreira, A.C., Sa, R., et al., 2015. Leptin modulates human Sertoli cells acetate production and glycolytic profile: a novel mechanism of obesity-induced male infertility? Biochim. Biophys. Acta, 1852(9):1824-1832. http://dx.doi.org/10.1016/j.bbadis.2015.06.005

Modrich, P., 1991. Mechanisms and biological effects of mismatch repair. Annu. Rev. Genet., 25(1):229-253. http://dx.doi.org/10.1146/annurev.ge.25.120191.001305

Mukherjee, S., Ridgeway, A.D., Lamb, D.J., 2010. DNA mismatch repair and infertility. Curr. Opin. Urol., 20(6): 525-532. http://dx.doi.org/10.1097/MOU.0b013e32833f1c21

Muraki, Y., Banno, K., Yanokura, M., et al., 2009. Epigenetic DNA hypermethylation: clinical applications in endometrial cancer (Review). Oncol. Rep., 22(5):967-972. http://dx.doi.org/10.3892/or_00000523

Ni, B., Ma, H., Lin, Y., et al., 2014. Genetic variants in Ser-Arg protein-coding genes are associated with the risk of nonobstructive azoospermia in Chinese men. Fertil. Steril., 101(6):1711-1717. http://dx.doi.org/10.1016/j.fertnstert.2014.02.033

Niemitz, E.L., Feinberg, A.P., 2004. Epigenetics and assisted reproductive technology: a call for investigation. Am. J. Hum. Genet., 74(4):599-609. http://dx.doi.org/10.1086/382897

Oliveira, P.F., Martins, A.D., Moreira, A.C., et al., 2015. The Warburg effect revisited-lesson from the Sertoli cell. Med. Res. Rev., 35(1):126-151. http://dx.doi.org/10.1002/med.21325

Park, J.Y., Seong, S.J., Kim, T.J., et al., 2013. Pregnancy outcomes after fertility-sparing management in young women with early endometrial cancer. Obstet. Gynecol., 121(1):136-142. http://dx.doi.org/10.1097/AOG.0b013e31827a0643

Pashaiefar, H., Sheikhha, M.H., Kalantar, S.M., et al., 2013. Analysis of MLH3 C2531T polymorphism in Iranian women with unexplained infertility. Iran. J. Reprod. Med. 11(1):19-24.

Peltomaki, P., 2003. Role of DNA mismatch repair defects in the pathogenesis of human cancer. J. Clin. Oncol., 21(6): 1174-1179. http://dx.doi.org/10.1200/JCO.2003.04.060

Perry, J.R., Hsu, Y.H., Chasman, D.I., et al., 2014. DNA mismatch repair gene MSH6 implicated in determining age at natural menopause. Hum. Mol. Genet., 23(9):24902497. http://dx.doi.org/10.1093/hmg/ddt620

Pluciennik, A., Burdett, V., Baitinger, C., et al., 2013. Extrahelical $(\mathrm{CAG}) /(\mathrm{CTG})$ triplet repeat elements support proliferating cell nuclear antigen loading and MutL $\alpha$ endonuclease activation. PNAS, 110(30):12277-12282. http://dx.doi.org/10.1073/pnas.1311325110

Richardson, M.E., Bleiziffer, A., Tuttelmann, F., et al., 2014. Epigenetic regulation of the RHOX homeobox gene cluster and its association with human male infertility. Hum. Mol. Genet., 23(1):12-23. http://dx.doi.org/10.1093/hmg/ddt392

Santucci-Darmanin, S., Neyton, S., Lespinasse, F., et al., 2002. The DNA mismatch-repair MLH3 protein interacts with MSH4 in meiotic cells, supporting a role for this MutL homolog in mammalian meiotic recombination. Hum. Mol. Genet., 11(15):1697-1706.

http://dx.doi.org/10.1093/hmg/11.15.1697

Serebrovska, Z.A., Serebrovskaya, T.V., Pyle, R.L., et al., 2006. Transmission of male infertility and intracytoplasmic sperm injection (mini-review). Fiziol. Zh., 52(3): 110-118.

Shih, K.K., Garg, K., Levine, D.A., et al., 2011. Clinicopathologic significance of DNA mismatch repair protein defects and endometrial cancer in women 40 years of age and younger. Gynecol. Oncol., 123(1):88-94. http://dx.doi.org/10.1016/j.ygyno.2011.06.005

Shimodaira, H., Yoshioka-Yamashita, A., Kolodner, R.D., et al., 2003. Interaction of mismatch repair protein PMS2 and the p53-related transcription factor $\mathrm{p} 73$ in apoptosis response to cisplatin. $P N A S, \mathbf{1 0 0 ( 5 ) : 2 4 2 0 - 2 4 2 5 .}$ http://dx.doi.org/10.1073/pnas.0438031100

Simon, L., Brunborg, G., Stevenson, M., et al., 2010. Clinical significance of sperm DNA damage in assisted reproduction outcome. Hum. Reprod., 25(7):1594-1608. http://dx.doi.org/10.1093/humrep/deq103

Sollars, V., Lu, X., Xiao, L., et al., 2003. Evidence for an epigenetic mechanism by which Hsp90 acts as a capacitor for morphological evolution. Nat. Genet., 33(1):70-74. http://dx.doi.org/10.1038/ng1067

Stojic, L., Cejka, P., Jiricny, J., 2005. High doses of SN1 type methylating agents activate DNA damage signaling cascades that are largely independent of mismatch repair. Cell Cycle, 4(3):473-477. http://dx.doi.org/10.4161/cc.4.3.1528

Surtees, J.A., Argueso, J.L., Alani, E., 2004. Mismatch repair proteins:key regulators of genetic recombination. Cytogenet. Genome Res., 107(3-4):146-159. http://dx.doi.org/10.1159/000080593

Terribas, E., Bonache, S., Garcia-Arevalo, M., et al., 2010. Changes in the expression profile of the meiosis-involved mismatch repair genes in impaired human spermatogenesis. J. Androl., 31(4):346-357. http://dx.doi.org/10.2164/jandrol.109.008805

Thompson, J.R., Williams, C.J., 2005. Genomic imprinting and assisted reproductive technology: connections and potential risks. Semin. Reprod. Med., 23(3):285-295. http://dx.doi.org/10.1055/s-2005-872457

Valentini, A.M., Armentano, R., Pirrelli, M., et al., 2006. Chemotherapeutic agents for colorectal cancer with a defective mismatch repair system: the state of the art. Cancer Treat. Rev., 32(8):607-618. http://dx.doi.org/10.1016/j.ctrv.2006.08.001

van Montfoort, A.P., Hanssen, L.L., de Sutter, P., et al., 2012. Assisted reproduction treatment and epigenetic inheritance. Hum. Reprod. Update, 18(2):171-197. http://dx.doi.org/10.1093/humupd/dmr047 
Wang, L.Y., Wang, N., Le, F., et al., 2013. Persistence and intergenerational transmission of differentially expressed genes in the testes of intracytoplasmic sperm injection conceived mice. J. Zhejiang Univ.-Sci. B (Biomed. \& Biotechnol.), 14(5):372-381.

http://dx.doi.org/10.1631/jzus.B1200321

Wang, Y., Qin, J., 2003. MSH2 and ATR form a signaling module and regulate two branches of the damage response to DNA methylation. PNAS, 100(26):15387-15392. http://dx.doi.org/10.1073/pnas.2536810100

Watson, P., Lynch, H.T., 1994. The tumor spectrum in HNPCC. Anticancer Res., 14(4B):1635-1639.

Wei, K., Clark, A.B., Wong, E., et al., 2003. Inactivation of Exonuclease 1 in mice results in DNA mismatch repair defects, increased cancer susceptibility, and male and female sterility. Genes Dev., 17(5):603-614. http://dx.doi.org/10.1101/gad.1060603

Win, A.K., Dowty, J.G., Antill, Y.C., et al., 2011. Body mass index in early adulthood and endometrial cancer risk for mismatch repair gene mutation carriers. Obstet. Gynecol., 117(4):899-905. http://dx.doi.org/10.1097/AOG.0b013e3182110ea3

Woldringh, G.H., Besselink, D.E., Tillema, A.H., et al., 2010. Karyotyping, congenital anomalies and follow-up of children after intracytoplasmic sperm injection with non-ejaculated sperm: a systematic review. Hum. Reprod. Update, 16(1):12-19.

http://dx.doi.org/10.1093/humupd/dmp030

Wu, Y., Berends, M.J., Sijmons, R.H., et al., 2001. A role for MLH3 in hereditary nonpolyposis colorectal cancer. Nat. Genet., 29(2):137-138. http://dx.doi.org/10.1038/ng1001-137

Xu, K., Lu, T., Zhou, H., et al., 2010. The role of MSH5 C85T and MLH3 C2531T polymorphisms in the risk of male infertility with azoospermia or severe oligozoospermia. Clin. Chim. Acta, 411(1-2):49-52. http://dx.doi.org/10.1016/j.cca.2009.09.038

Yi, W., Wu, X., Lee, T.H., et al., 2005. Two variants of MutS homolog hMSH5: prevalence in humans and effects on protein interaction. Biochem. Biophys. Res. Commun., 332(2):524-532.

http://dx.doi.org/10.1016/j.bbrc.2005.04.154

Youn, C.K., Cho, H.J., Kim, S.H., et al., 2005. Bcl-2 expression suppresses mismatch repair activity through inhibition of E2F transcriptional activity. Nat. Cell Biol., 7(2):137-147. http://dx.doi.org/10.1038/ncb1215

Zheng, P., Schramm, R.D., Latham, K.E., 2005. Developmental regulation and in vitro culture effects on expression of DNA repair and cell cycle checkpoint control genes in rhesus monkey oocytes and embryos. Biol. Reprod., 72(6):1359-1369.

http://dx.doi.org/10.1095/biolreprod.104.039073

Zheng, Y.M., Li, L., Zhou, L.M., et al., 2013. Alterations in the frequency of trinucleotide repeat dynamic mutations in offspring conceived through assisted reproductive technology. Hum. Reprod., 28(9):2570-2580. http://dx.doi.org/10.1093/humrep/det294

\section{中文概要}

题 目: DNA 错配修复系统的改变对人类生育能力及相 关治疗的影响

概 要: 简要概括 DNA 损伤修复系统在人体中的作用和 机制, 并探讨其改变与人类生殖能力以及通过辅 助生殖技术诞生的子代之间的相互影响。希望更 多相关工作的进行能够为人类不孕症的预防、诊 断和治疗工作建立一个更好的医疗体系。

关键 词: DNA 错配修复; 不孕; 辅助生殖技术; 后代 